\title{
Molecular detection and characterization of cpb2 gene in Clostridium perfringens isolates from healthy and diseased chickens
}

Tolooe A (1), Shojadoost B (1), Peighambari SM (1)

(1) Department of Clinical Sciences, Faculty of Veterinary Medicine, University of Tehran, Tehran, Iran.

\begin{abstract}
Clostridium perfringens is an important pathogen in both human and veterinary medicine. Necrotic enteritis (NE) is the most clinically dramatic bacterial enteric disease of poultry induced by $C$. perfringens. The pathogenicity of this bacterium is associated with the production of extracellular toxins produced by some of its strains, such as beta2 toxin. The exact role of beta2 toxin in NE pathogenesis is still controversial. In the present study, C. perfringens isolates from healthy and diseased poultry flocks from different parts of Iran were analyzed by PCR assay to determine the presence of all variants of the beta2 toxin gene (cpb2). The products of two positive $c p b 2$ PCR reactions were sequenced, compared to each other and to the $c p b 2$ sequences published in GenBank (by multiple alignment and phylogenetic analysis). The current work represents the first study of $c p b 2$ in poultry C. perfringens isolates in Asia, and reports the highest percentage of $c p b 2$-positive isolates in both apparently healthy chickens (97.7\%) and those afflicted with NE (94.4\%). The sequenced isolates were classified as atypical. This study did not show a direct correlation between NE occurrence and cpb2 presence.
\end{abstract}

Key words: Clostridium perfringens, necrotic enteritis, chicken, beta2 toxin, cpb2, Iran.

\section{INTRODUCTION}

Clostridium perfringens, an anaerobic grampositive bacterium, is an important pathogen among humans and many other animal species (1). In poultry, it can cause a deadly disease called necrotic enteritis (NE). Worldwide economic losses to the poultry industry due to NE have been estimated at more than two billion dollars annually (2). The pathogenicity of $C$. perfringens has contributed to the production of various extracellular toxins and enzymes. However, the exact mechanism behind the pathogenesis of $C$. perfringens is poorly understood $(3,4)$. Clostridium perfringens is classified into five toxin types (A to E) based on differential production of the four major toxins, alpha, beta, epsilon, and iota (1). NE is caused primarily by $C$. perfringens type A and, to a lesser extent, type C strains (3,
4). In addition to the so-called major toxins, there are at least 13 minor toxins or enzymes produced by some strains of $C$. perfringens, which may play a role in pathogenicity. These compounds include beta2, netB, delta, theta, kappa, lambda, $\mathrm{mu}, \mathrm{nu}$, gamma, eta, neuraminidase, urease and enterotoxin $(1,3)$. While the roles of beta, iota, and epsilon toxins in enteritis pathogenesis among animals are well documented, the roles of other toxins, such as alpha, netB, and beta 2 toxin, in NE pathogenesis are still unclear (3-7).

Almost a decade ago, the beta2 toxin and its encoding gene (cpb2) were first identified in $C$. perfringens type C (strain CWC245) isolated from a piglet with necrotizing enterocolitis (8). The amino acid sequence of $c p b 2$ showed no significant homologies with $c p b$ from the beta toxin (15\%) or other known proteins $(8,9)$. Although its biological activity was similar to that of the beta 
toxin it may possess weaker cytotoxic activity (8). A possible pore formation or other mechanisms leading to cell membrane disruption appear to be its most plausible function (1). The $c p b 2$ gene was shown to be located on a plasmid (1) and two alleles of the $c p b 2$ gene were described (10, 11). The original $c p b 2$ was termed the consensus gene/allele whereas the variant was denominated the atypical gene or atypical allele $(11,12)$. The consensus $c p b 2$ allele has been identified in porcine isolates of $C$. perfringens, while the atypical allele was present predominantly in isolates from nonporcine hosts $(11,13)$. The $c p b 2$ gene has been found in isolates originating from humans and a variety of other animals. Numerous published studies have addressed a possible association between $c p b 2$-harboring strains of $C$. perfringens and the occurrence of enteric disease. However, it is not clear whether beta2 toxin is involved in $C$. perfringens-associated avian enteric diseases (14).

However, no study has been published in Iran or any other Asian country regarding the $c p b 2$ harboring strains of $C$. perfringens from poultry sources. In the present study, C. perfringens isolates from healthy and diseased poultry flocks from different parts of Iran were analyzed by PCR assay in order to determine the presence of both consensus and atypical cpb2 genes. The products of two positive $c p b 2 \mathrm{PCR}$ reactions were sequenced; comparison of these sequences to each other and to the cpb2 sequences available in GenBank was made by multiple alignment and phylogenetic analysis.

\section{MATERIALS AND METHODS}

\section{Bacterial Isolates and Bacteriological Procedures}

A set of frozen (in $50 \%$ glycerol at $-70^{\circ} \mathrm{C}$ ) isolates of $C$. perfringens type A collected from 2005 to 2008 in our laboratory was used for this study (unpublished data). The collection consisted of 36 isolates obtained from six NE-positive flocks and 43 strains obtained from four NEnegative flocks. The frozen $C$. perfringens isolates were cultivated in brain heart infusion (BHI) and incubated anaerobically at $37^{\circ} \mathrm{C}$ for 24 to 36 hours. Samples were subcultured anaerobically in blood agar plates containing 7\% defibrinated sheep blood, tryptose sulfite cycloserine agar (TSC) and tryptose sulfite neomycin agar (TSN). The identity of the isolates was confirmed by characteristic colony morphology, hemolytic pattern, Gram staining, and biochemical tests as previously described (15). All culture media and additives used in this study were obtained from Merck (Germany). Reference strains of Clostridium perfringens CIP 60.61 (type B, cpb2positive) were used as a positive control whereas Clostridium perfringens ATCC 13124 (Type A, $c p b 2$ negative) served as a negative control (Rasta Daroo Co., Iran).

\section{PCR Reaction}

To extract bacterial DNA, a few colonies of each C. perfringens isolate grown overnight on blood agarplateat $37^{\circ} \mathrm{C}$ weresuspended in $100 \mu \mathrm{Ldistilled}$ water in a clean $1.5 \mathrm{~mL}$ microtube, boiled for ten minutes and centrifuged for ten minutes at 10,000 $\mathrm{x} g$. The supernatants were carefully removed and used as template DNA. The DNA concentration was determined by BioPhotometer ${ }^{\circledast}$ (Eppendorf AG, Germany) and adjusted to approximately $50 \mathrm{ng}$ for each PCR reaction. To detect all variants of cpb2 gene (consensus/ atypical), previously developed forward (5'-AAATATGATCCTAACCAACAA-3') and reverse (5'-CCAAATACTCTAATCGATGC-3') primers were used (16).

Amplification reactions were carried out in a $50 \mu \mathrm{L}$ reaction volume containing: $5 \mu \mathrm{L} 10 \mathrm{x}$ PCR buffer, $25 \mathrm{mM} \mathrm{MgCl}, 5 \mathrm{mM}$ dNTP mixture, five units of Taq DNA polymerase, $0.4 \mu \mathrm{M}$ of each primer, $\mathrm{dH} 2 \mathrm{O}$ and $10 \mu \mathrm{L}$ of template DNA solution. Positive and negative controls using template DNA prepared from appropriate bacterial strains as described above were included in all PCR reaction sets. Amplification was programmed in a thermocycler (Gradient Mastercycler, Germany) as follows: $95^{\circ} \mathrm{C}$ for 15 minutes followed by 40 cycles of $94^{\circ} \mathrm{C}$ for 30 seconds, $53^{\circ} \mathrm{C}$ for 90 seconds, $72^{\circ} \mathrm{C}$ for 90 seconds, and a final extension at $72^{\circ} \mathrm{C}$ for ten minutes (17). The amplification products were detected by gel electrophoresis (Apelex, France) in $1.5 \%$ agarose gel in $1 \times$ TAE buffer, stained with 0.5 $\mu \mathrm{g} / \mathrm{mL}$ EtBr. Amplified bands were visualized and photographed under UV transillumination. The primers and other materials used in PCR reactions were provided by Cinnagen (Tehran, Iran).

\section{Sequence and Phylogenetic Analysis}

After the selection of two Clostridium perfringens isolates (ATBS61tIR and ATBS100tIR) obtained from separate diseased flocks, their 
relevant PCR amplified products for cpb2 were purified using the GeneJET ${ }^{\circledast}$ Gel Extraction kit (Fermentas Life Science, Germany) and submitted for automated sequencing in both directions at the Geneservice ${ }^{\oplus}$, Source BioSience (Cambridge, England) using PCR primers as sequencing primers. Nucleotide and predicted amino acid sequence data were aligned by the Clustal alignment algorithm. The COBALT multiple alignment tool (http://www.ncbi.nlm. nih.gov/tools/cobalt) was used for amino acid alignments.

Phylogenetic analysis based on nucleotide sequences was conducted using the distance method, UPGMA (unweighted pair group with arithmetic mean), by calculating bootstrap values for 1000 replicates in a CLC Sequence Viewer ${ }^{\oplus}$, version 6.4 (CLC Bio, Denmark). The sequence data were submitted to GenBank under the accession numbers GU581184 (ATBS61tIR strain) and GU581185 (ATBS100tIR strain). The following accession numbers for $C$. perfringens beta2-toxin gene sequences were employed for multiple alignment and phylogenetic analyses: AY609162 (JGS1604 strain, a non-porcine isolate representative of atypical beta2-toxin sequence), L77965 (CWC245 strain, a porcine isolate representative of consensus beta2-toxin sequence), AY884035 (ARS-CP13 strain, a poultry isolate), AY884036 (ARS-CP25 strain, isolated from poultry), AY884037 (ARS-CP30 strain, a poultry isolate), AY884038 (ARS-CP38 strain, also a poultry isolate), AY884039 (ARSCP39 strain, a poultry isolate), AY884040 (ARS-
CP40 strain, isolated from poultry), AY884041 (ARS-CP42 strain, a poultry isolate), AJ537533 (CF5 strain, a porcine isolate), DQ525205 (47001c12 strain, an isolate from enterotoxemic cattle), AJ537534 (E482/97 strain, a horse isolate), AY730631(F4406 strain, an isolate from a human with gastrointestinal disease) and AY730634 (F4589 strain, an isolate from a human with gastrointestinal disease).

\section{RESULTS}

\section{PCR}

All isolates were examined for the presence of the $c p b 2$ gene by single PCR (Figure 1). Out of 36 isolates obtained from diseased flocks, 34 were positive $(94.4 \%)$ for the $c p b 2$ gene. Two isolates that were negative for $c p b 2$ had been obtained from a single farm. Out of 43 isolates obtained from healthy flocks, 42 were cpb2-positive $(97.7 \%)$.

\section{Sequence and Phylogenetic Analysis}

Comparison of two Iranian $C$. perfringens isolates, ATBS61tIR and ATBS100tIR, sequenced by Blast-N at the nucleotide level revealed $99 \%$ similarity to each other and 73 to $100 \%$ identity with the $c p b 2$ sequences of $C$. perfringens strains available in GenBank. Nucleotide sequences differed at positions $6,10,12,20$, and 198 between the two Iranian $C$. perfringens isolates. The five differences found between ATBS61tIR and JGS1604 were at positions 11, 12, 22, 67, and 198, whereas four differences were detected

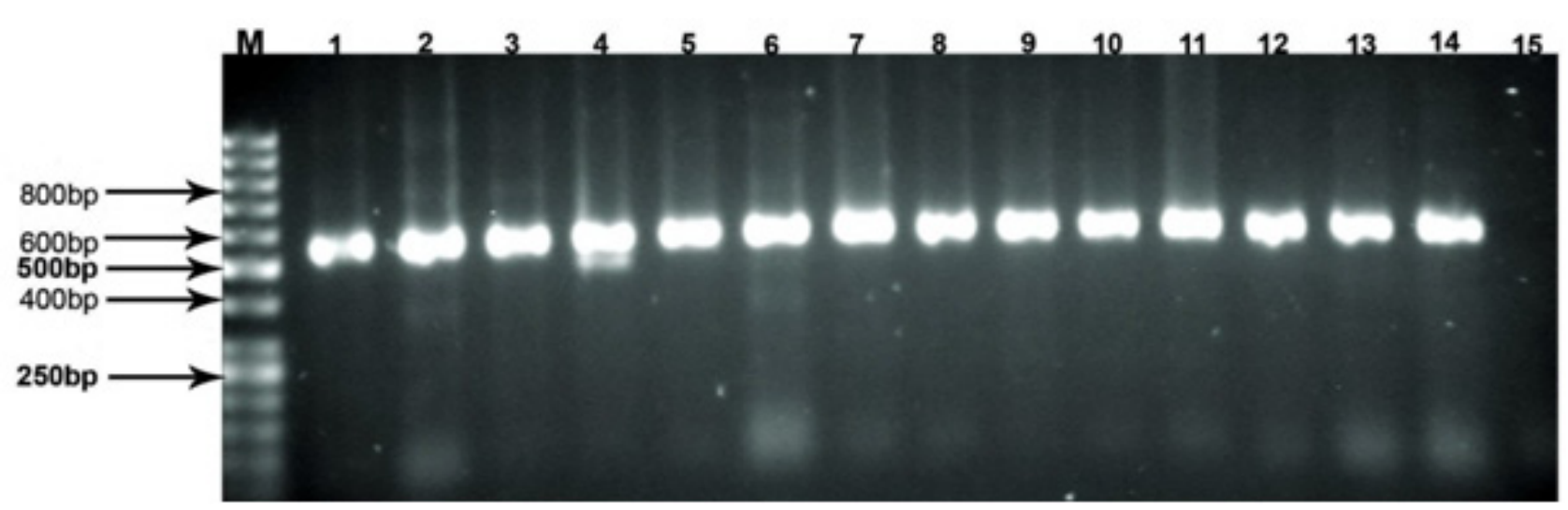

Figure 1. Agarose gel (1.5\%) electrophoresis results of the PCR assay to detect a $548 \mathrm{bp}$ fragment of the $c p b 2$ gene in C. perfringens. Lane M: size marker (GeneRuler 50 bp DNA Ladder, Fermentas); lane 1: positive control for $c p b 2$ gene (CIP 60.61); lanes 2 to 14: $c p b 2$-positive C. perfringens isolates from healthy and diseased chickens; lane 15: negative control (ATCC 13124) 
between ATBS100tIR and JGS1604 at positions $6,10,11$, and 67 . There were many differences between CWC245 strain and two Iranian isolates. CWC245 strain differed in 137 and 138 positions with ATBS61tIR and ATBS100tIR, respectively. Both Iranian isolates differed with strain JGS1604 at positions 11 and 67 .

Figure 2 shows an amino acid alignment of the atypical beta2-toxin protein (JGS1604), two
Iranian isolates (ATBS61tIR and ATBS100tIR), and the consensus beta2-toxin protein (CWC245). The beta2-toxin protein sequences of Iranian isolates were $97 \%$ identical to each other, and 93\% identical to atypical beta2-toxin proteins whereas they displayed only 66 to $67 \%$ identity with the consensus beta2-toxin protein. Comparison of amino acid substitutions at different positions between Iranian field isolates

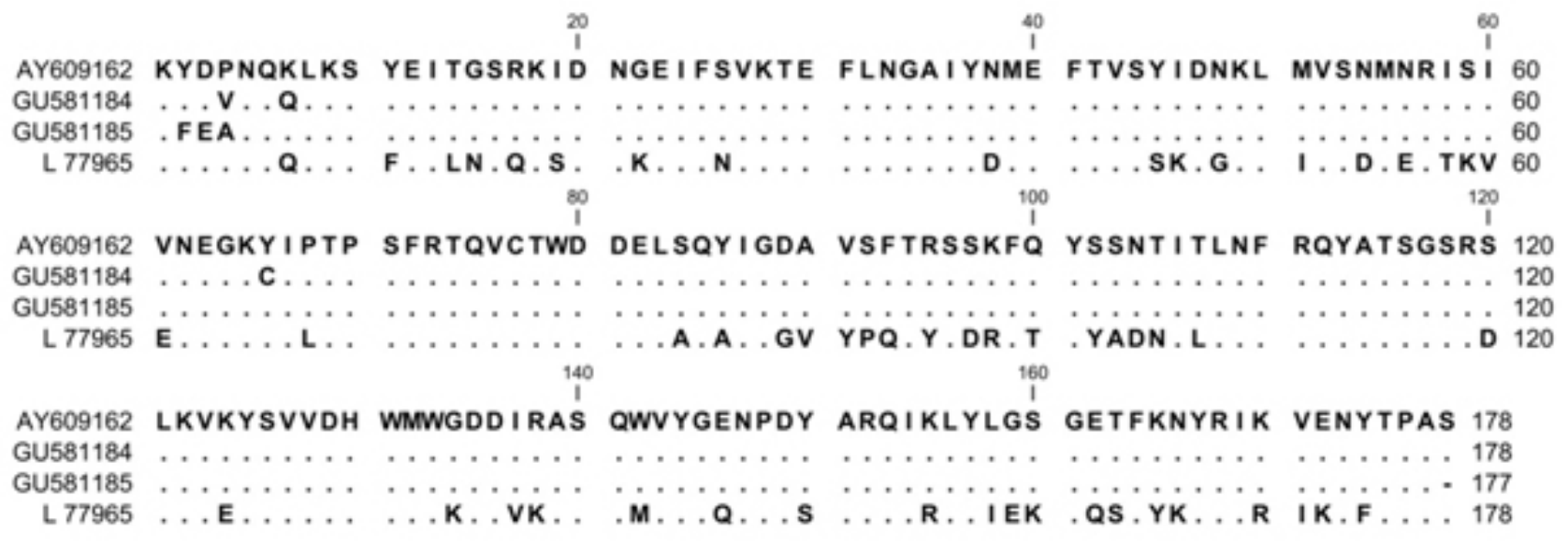

Figure 2. Amino acid alignment of beta2-toxin proteins from two Iranian C. perfringens isolates and the representative strains of consensus (CWC245) and atypical (JGS1604) types. Dots indicate sequences identical to those of the JGS1604 strain.

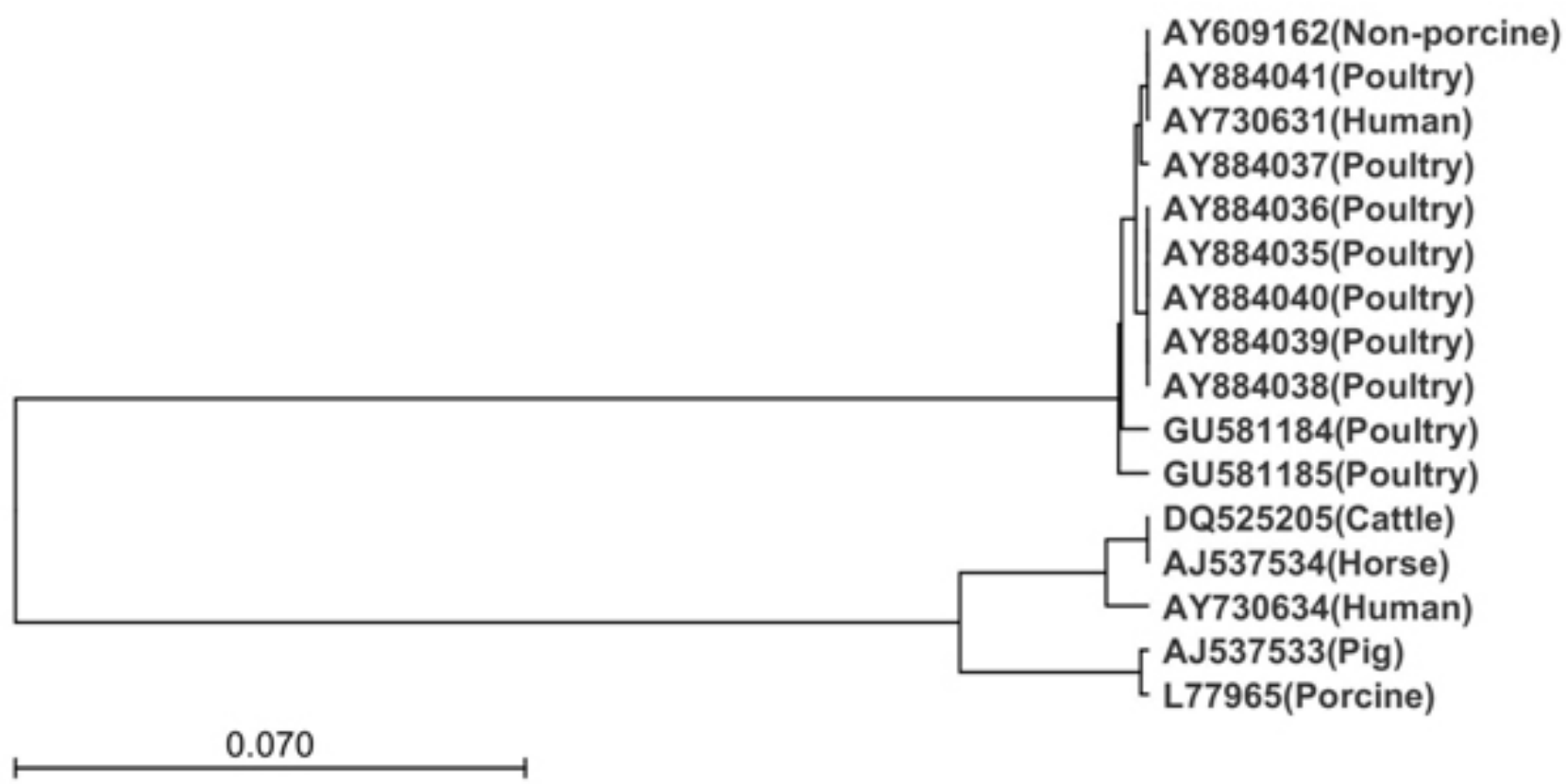

Figure 3. Phylogenetic tree of nucleotide sequence from the 532-bp cpb2 gene fragment of two Iranian $C$. perfringens field isolates and C. perfringens strains from various hosts published in GenBank. The tree was constructed by the Clustal method by calculating bootstrap values for 1000 replicates. Branched distances correspond to sequence divergence. 
showed five differences at positions 2, 3, 4, 7, and 66. Strain JGS1604 differed from ATBS61tIR at positions 4, 7 and 66, and from ATBS100tIR at positions 2, 3 and 4, whereas strain CWC245 differed from ATBS61tIR, ATBS100tIR and JGS1604 at amino acid positions 57, 59 and 56, respectively (Figure 2 ).

The phylogenetic tree based on nucleotide sequences from a $c p b 2$ gene fragment of two Iranian $C$. perfringens isolates and some $C$. perfringens isolates from various hosts is shown in Figure 3. Phylogenetic analysis separated the isolates into two groups, atypical and consensus $c p b 2$ genes. Among atypical group, two Iranian isolates, ATBS61tIR and ATBS100tIR, formed two separate branches and were more closely related to other isolates from poultry sources. Among the consensus group, isolates obtained from cattle and horses formed a separate branch and showed closer relation to the human isolate (F4589) than to porcine origin isolates (CWC245 and CF5) which also formed a separate branch (Figure 3). Another human isolate (F4406) was classified among the atypical group and formed a joint branch with poultry (ARS-CP42) and non-porcine (JGS1604) isolates.

\section{DISCUSSION}

Throughout the last decade, several epidemiological studies have shown a wide distribution of $\beta 2$-toxigenic $C$. perfringens strains among various healthy and diseased humans and other animal species. Clostridium perfringens-harboring $c p b 2$ has been isolated from pigs, horses, cattle, small ruminant animals, domestic carnivores, many wildlife species, fish, poultry and humans $(14,18)$. Based on these studies the correlation between $c p b 2$ gene prevalence and gastrointestinal disease was strong in pigs and somewhat weaker in horses; but no conclusions could be drawn as to the role of the $\beta 2$-toxin in enteric disease in humans or other animal species $(14,18)$.

The prevalence of the $c p b 2$ gene in avian isolates has varied among descriptions in the literature. The highest (23 out of 31 ) and lowest ( 0 out of 41) prevalences of the cpb2 gene among diseased birds were reported in prior studies $(19,20)$. In our study, 34 out of 36 isolates from diseased flocks tested positive. The extent to which the cpb2 gene has been found in isolates from healthy flocks has also varied. Both high (46 out of 48) and low prevalences (4 out of 27) of the $c p b 2$ gene were previously shown in isolates from healthy flocks $(21,22)$. In the present study, we found 42 out of 43 isolates positive for the $c p b 2$ gene.

The detection sensitivity of the various alleles of $c p b 2$ has contributed to the primer sequences employed for amplification (16). Several sets of primer sequences have been applied for amplification of the $c p b 2$ gene. However, most of these primers were able to detect only a consensus or atypical form of the $c p b 2$ gene. This might indicate that the number of $c p b 2$-positive or cpb2-negative C. perfringens isolates reported previously could be somewhat lower than the actual numbers. In the present study, we used primers capable of amplifying all known variants of $c p b 2$ sequences. Perhaps one of the reasons for the high $c p b 2$-gene prevalence among isolates of this study was the utilization of appropriate primers in the PCR reaction.

Our findings based on phylogenetic analyses and amino acid alignment demonstrated that two Iranian $C$. perfringens were far from the consensus representative strain (CWC245), but very close to the atypical representative strain (JGS1604). The protein sequences in the Iranian isolates were $93 \%$ identical to the JGS1604 strain versus only $66 \%$ to $67 \%$ identity with the CWC245 strain. These results almost corresponded to a previous finding that the protein encoded by atypical cpb2 genes had $62.3 \%$ identity with the consensus beta 2 toxin (11). Comparison of sequences of two Iranian isolates with other $c p b 2$ gene sequences among atypical and consensus groups revealed $99 \%$ and $74 \%$ identity at the nucleotide level, respectively. In a phylogenetic tree, Iranian isolates were placed in two separate but adjacent branches. This finding may be explained under the assumption that these isolates were taken from two different flocks originating in geographically separate areas of Iran. It appears that the type of $c p b 2$ alleles may differ in distinct geographical locations $(22,23)$. Siragusa et al. (22) reported the presence of the atypical $c p b 2$ allele among North American C. perfringens isolates, whereas Johansson et al. (23) found that the European $C$. perfringens isolates carried the consensus $c p b 2$ allele. 
It should be noted that the mere presence of $C$. perfringens beta2 toxin gene does not necessarily imply the actual expression of the protein. It has been found that consensus genes from porcine isolates are expressed in most cases (>96.9\%); however, it was reported that about half of the consensus genes from non-porcine $C$. perfringens isolates were not expressed due to a frameshift mutation (11). Interestingly, there has been only one report on the expression of the atypical genes among non-porcine $C$. perfringens isolates (24). We found only one study that reported $c p b 2$ expression in avian $C$. perfringens isolates. Crespo et al. (20) reported that 54\% of the avian $C$. perfringens isolates positive for $c p b 2$ gene produced the beta2 toxin in vitro. In that study the type of $c p b 2$ allele (consensus or atypical) was not clear.

To the best of our knowledge, the present study is the first investigation on $C$. perfringens isolates from poultry in Iran as well as the first on detection of the beta 2 toxin gene in all of Asia. We are reporting the highest percentage of $c p b 2$ gene presence in C. perfringens isolates in both healthy and diseased chickens. We also found that the number of $c p b 2$-harboring isolates was equally distributed between NE-positive and healthy birds. Surveillance of healthy chickens and those with NE has not revealed a direct correlation between occurrence of the disease and presence of $c p b 2$ gene. The two Iranian isolates sequenced for $c p b 2$ were atypical.

Future investigations are required to elucidate the role of beta 2 toxin in the induction of NE, the ability of the $c p b 2$ gene to produce toxin and the regulatory mechanisms involved in the expression of beta2 toxin.

\section{ACKNOWLEDGMENTS}

The authors are especially grateful to Prof. J. Glenn Songer (University of Arizona, Tucson, AZ) for his helpful suggestions and comments at different stages of this research.

\section{COPYRIGHT}

(c) CEVAP 2011

\section{SUBMISSION STATUS}

Received: August 8, 2010.

Accepted: January 25, 2011.

Abstract published online: January 26, 2011. Full paper published online: February 28, 2011.

\section{CONFLICTS OF INTEREST}

There is no conflict.

\section{FINANCIAL SOURCE}

The Research Council of the University of Tehran provided the financial grant (protocol $n$. 7508049/6/7).

\section{ETHICS COMMITTEE APPROVAL}

The present study was approved by the Research Committee of the Faculty of Veterinary Medicine, University of Tehran.

\section{CORRESPONDENCE TO}

BAHRAM SHOJADOOST, Department of Clinical Sciences, Faculty of Veterinary Medicine, University of Tehran, Tehran, PO Box 141556453, Iran. Phone: 009821 6111-7150. Fax: 0098 216693 3222. Email: bshojae@ut.ac.ir.

\section{REFERENCES}

1. Petit L, Gibert M, Popoff MR. Clostridium perfringens: toxinotype and genotype. Trends Microbiol. 1999;7(3):104-10.

2. McReynolds JL, Byrd JA, Anderson RC, Moore RW, Edrington TS, Genovese KJ, et al. Evaluation of immunosuppressants and dietary mechanisms in an experimental disease model for necrotic enteritis. Poult Sci. 2004;83(12):1948-52.

3. Cooper KK, Songer JG. Necrotic enteritis in chickens: a paradigm of enteric infection by Clostridium perfringens type A. Anaerobe. 2009;15(1-2):55-60.

4. Van Immerseel F, Rood JI, Moore RJ, Titball RW. Rethinking our understanding of the pathogenesis of necrotic enteritis in chickens. Trends Microbiol. 2009;17(1):32-6.

5. Songer JG. Clostridial enteric diseases of domestic animals. Clin Microbiol Rev. 1996;9(2):216-34.

6. Keyburn AL, Boyce JD, Vaz P, Bannam TL, Ford ME, Parker D, et al. NetB, a new toxin that is associated with avian necrotic enteritis caused by Clostridium perfringens. PLoS Pathog. 2008;4(2):e26.

7. Keyburn AL, Sheedy SA, Ford ME, Williamson MM, Awad MM, Rood JI, Moore RJ. Alpha-toxin of Clostridium perfringens is not an essential virulence factor in necrotic enteritis in chickens. Infect Immun. 2006;74(11):6496-500.

8. Gibert M, Jolivet-Reynaud C, Popoff MR. Beta2 toxin, a novel toxin produced by Clostridium perfringens. Gene. 1997;203(1):65-73.

9. Shimizu T, Ohtani K, Hirakawa H, Ohshima K, Yamashita A, Shiba T, et al. Complete 
genome sequence of Clostridium perfringens, an anaerobic flesh-eater. Proc Natl Acad Sci USA. 2002;99(2):996-1001.

10. Fisher DJ, Miyamoto K, Harrison B, Akimoto S, Sarker MR, McClane BA. Association of beta2 toxin production with Clostridium perfringens type A human gastrointestinal disease isolates carrying a plasmid enterotoxin gene. Mol Microbiol. 2005;56(3):747-62.

11. Jost BH, Billington SJ, Trinh HT, Bueschel DM, Songer JG. Atypical cpb2 genes, encoding beta2-toxin in Clostridium perfringens isolates of nonporcine origin. Infect Immun. 2005;73(1):652-6.

12. Jost BH, Billington SJ, Trinh HT, Songer JG. Association of genes encoding beta2 toxin and a collagen binding protein in Clostridium perfringens isolates of porcine origin. Vet Microbiol. 2006;115(1-3):173-82.

13. Bueschel DM, Jost BH, Billington SJ, Trinh HT, Songer JG. Prevalence of cpb2, encoding beta2 toxin, in Clostridium perfringens field isolates: correlation of genotype with phenotype. Vet Microbiol. 2003;94(2):121-9.

14. van Asten AJAM, Nikolaou GN, Gröne A. The occurrence of cpb2-toxigenic Clostridium perfringens and the possible role of the $\beta 2$-toxin in enteric disease of domestic animals, wild animals and humans. Vet J. 2010;183(2):135-40.

15. Quinn PJ, Carter ME, Markey B, Carter GR. Clinical veterinary microbiology. London: Wolfe Publishing, 1994. 191-208 p.

16. van Asten AJAM, Allaart JG, Meeles AD, Gloudemans PW, Houwers DJ, Gröne A. A new PCR followed by MboI digestion for the detection of all variants of the Clostridium perfringens $\mathrm{cpb} 2$ gene. Vet Microbiol. 2008;127(3-4):412-6.

17. van Asten AJ, van der Wiel CW, Nikolaou G, Houwers DJ, Gröne A. A multiplex PCR for toxin typing of Clostridium perfringens isolates. Vet Microbiol. 2009;136(3-4):411-2.
18. Schotte U, Truyen U, Neubauer H. Significance of $\beta 2$-toxigenic Clostridium perfringens infections in animals and their predisposing factors - a review. J Vet Med B. 2004;51(10):423-6.

19. Chalmers G, Bruce HL, Hunter DB, Parreira VR, Kulkarni RR, Jiang YF, et al. Multilocus sequence typing analysis of Clostridium perfringens isolates from necrotic enteritis outbreaks in broiler chicken populations. J Clin Microbiol. 2008;46(12):3957-64.

20. Crespo R, Fisher DJ, Shivaprasad HL, FernándezMiyakawa ME, Uzal FA. Toxinotypes of Clostridium perfringens isolated from sick and healthy avian species. J Vet Diagn Invest. 2007;19(3):329-33.

21. Gholamiandekhordi AR, Ducatelle R, Heyndrickx M, Haesebrouck F, Van Immerseel F. Molecular and phenotypical characterization of Clostridium perfringens isolates from poultry flocks with different disease status. Vet Microbiol. 2006;113(1-2):143-52.

22. Siragusa GR, Danyluk MD, Heitt KL, Wise MG, Craven SE. Molecular subtyping of poultryassociated type A Clostridium perfringens isolates by repetitive-element PCR. J Clin Microbiol. 2006;44(3):1065-73.

23. Johansson A, Aspan A, Bagge E, Baverud V, Engstrom BE, Johansson KE. Genetic diversity of Clostridium perfringens type A isolates from animals, food poisoning outbreaks and sludge. BMC Microbiol. 2006;6(1):47.

24. Lebrun M, Filée P, Mousset B, Desmecht D, Galleni M, Mainil JG, Linden A. The expression of Clostridium perfringens consensus beta2 toxin is associated with bovine enterotoxaemia syndrome. Vet Microbiol. 2007;120(1-2):151-7. 